\title{
Surto de babesiose cerebral em bovinos no Estado do Rio Grande do Sul
}

\author{
Cerebral babesiosis outbreak in bovines in the State of Rio Grande do Sul, Brazil
}

\author{
Nadia Aline Bobbi Antoniassi ${ }^{\mathrm{I}}$ André Mendes Ribeiro Corrêa ${ }^{\mathrm{I}}$ Adriana da Silva Santos ${ }^{\mathrm{I}}$ \\ Saulo Petinatti Pavarini ${ }^{\mathrm{I}}$ Luciana Sonne ${ }^{\mathrm{I}}$ Paulo Mota Bandarra ${ }^{\mathrm{I}}$ David Driemeier $^{*}$
}

\begin{abstract}
Descreve-se um surto de mortalidade em bovinos por Babesia bovis em abril de 2007, no Município de Picada Café, Rio Grande do Sul. Em um rebanho com 55 novilhas, 28 (50,9\%) morreram em cinco dias. A doença iniciou vinte dias após o ingresso dos bovinos na propriedade. Os sinais clínicos incluíam febre, incoordenação, agressividade, anemia, petéquias nas mucosas e morte 1 á 2 dias após. Em 4 animais necropsiados, observaram-se palidez de mucosas, hemorragias múltiplas, esplenomegalia, fígado aumentado e alaranjado, vesícula biliar com parede edemaciada e contendo bile grumosa. Os rins estavam vermelho-escuros e a bexiga continha urina cor de vinho tinto. O encéfalo apresentou cor róseocereja externamente e ao corte, mais marcado no córtex telencefálico, cerebelo e corpo estriado, contrastando com a cor branca da substância branca. Na histologia havia nefrose hemoglobinúrica, necrose hepática paracentral, bilestase canalicular, congestão esplênica, além de congestão com grande quantidade de eritrócitos parasitados por estruturas compatíveis com Babesia bovis na região cortical do encéfalo, também observadas em esfregaços teciduais dessas regiões. A morte de 28 bovinos em 5 dias deveu-se, provavelmente, à falta de imunidade contra o parasito. $O$ tratamento foi realizado com dipropionato de imidocarb nos demais animais, havendo recuperação dos bovinos que apresentavam sinais iniciais leves e não ocorrência de novos casos durante um período de dois meses, quando foram enviados para abate.
\end{abstract}

Palavras-chave: Babesia bovis, babesiose cerebral, bovinos.

\section{ABSTRACT}

An outbreak of cattle mortality due to Babesia bovis infection in the county of Picada Café, Rio Grande do Sul, southern Brazil, in April 2007 is described. Twenty eight heifers (50.9\%) died, out of a herd of 55 animals, in five days. The disease occurred approximately 20 days after heifers were transferred to this farm. The clinical signs included fever, anemia, aggressiveness, incoordination, petechiae in the mucous membranes and death after 1 to 2 days. The necropsy revealed pale mucous membranes, splenomegaly, enlarged and yellowish liver, congested and edematous gall bladder containing viscous granular bile. The kidneys and urine were dark red. The gray matter of cerebrum and cerebellum had a characteristic cherry-pink color. Hemorrhage was seen in the epicardium and endocardium. The histological findings consisted of hemoglobinuric nephrosis, paracentral hepatic necrosis, bile stasis, spleen congestion. The gray matter of the brain exhibited congestion with erythrocytes parasitized by Babesia bovis, which were also seen in the brain impression smear. The death of 28 heifers in 5 days was attributed to inadequate immunity against the parasite. The application of imidocarb dipropionate in animals presenting the initial stage of the disease and in all other animals of the herd was adopted as preventive treatment and no new cases of the disease happened in the next two months, when they were sent to slaughter.

Key words: Babesia bovis, cerebral babesiosis, cattle.

A babesiose bovina, uma doenças importante em regiões tropicais (RADOSTITS et al., 2002), é causada pelos protozoários Babesia bovis e Babesia bigemina inoculados pelo carrapato Rhipicephalus (Boophilus) microplus (SOARES et al., 2000; FARIAS, 2001). No Brasil, é endêmica e causa prejuízos econômicos em áreas de instabilidade

ISetor de Patologia Veterinária, Universidade Federal do Rio Grande do Sul (SPV-UFRGS). Av. Bento Gonçalves, 9090, Agronomia, 91540-000, Porto Alegre, RS, Brasil. E-mail: davetpat@ufrgs.br. *Autor para correspondência 
enzoótica, sendo frequente no sul do país (FARIAS, 2001; ALMEIDA et al., 2005; RODRIGUES et al., 2005).

A B. bovis é o agente mais frequentemente envolvido em casos de babesiose e responsável por $41 \%$ dos casos clínicos de tristeza parasitária bovina da Região Sul do Rio Grande do Sul, no período de 1978 a 2005 (ALMEIDA et al., 2005).

Alguns fatores influenciam na dinâmica da infecção por Babesia sp. como população de carrapatos e sua capacidade de transmissão e susceptibilidade dos bovinos, de acordo com a raça, idade, estado fisiológico e imunitário (SOARES et al., 2000). O período de incubação varia de 7 a 20 dias (RADOSTITS et al., 2002). Os sinais clínicos são decorrentes da multiplicação dos protozoários em hemácias e consequente hemólise (De VOS, 2004; RADOSTITS et al., 2002), consistindo em febre, palidez de mucosas, icterícia, hemoglobinemia, hemoglobinúria e morte (ALMEIDA et al., 2005; RODRIGUES et al., 2005).

A babesiose cerebral é a manifestação clínica da infecção por B. bovis em que são observados sinais neurológicos como incoordenação motora, hiperexcitabilidade, opistótono, cegueira, tremores musculares, paralisia dos membros pélvicos, movimentos de pedalagem, andar em círculos, agressividade e coma (ALMEIDA et al., 2005; RODRIGUES et al., 2005). Essas alterações são provenientes do sequestro de eritrócitos parasitados nos capilares da substância cinzenta do encéfalo (CALLOW \& McGAVIN, 1963). Os casos neurológicos quase invariavelmente são fatais, ocorrendo após um curso clínico agudo ou superagudo que dura alguns minutos até 24-36 horas (BARROS et al., 2006).

No presente relato, descreve-se um surto de babesiose cerebral em bovinos ocorrido no Município de Picada Café, no Estado do Rio Grande do Sul, caracterizado por alta morbidade e letalidade.

Os dados epidemiológicos e clínicos foram obtidos junto ao proprietário e veterinário responsável. Durante visita à propriedade, quatro bovinos fêmeas, da raça Devon, com aproximadamente 2,5 anos foram necropsiados. Fragmentos de órgãos foram fixados em formalina a $10 \%$ e processados para exames histológicos. Esfregaços de córtex telencefálico dos cinco animais foram corados pelo Método Panótico ${ }^{\circledR}$ rápido.

No mês de abril de 2007, cinquenta e cinco novilhas, da raça Devon, com aproximadamente 2 anos e seis meses, foram transportados do Município de Tainhas para uma propriedade no Município de Picada Café, Rio Grande do Sul. Na fazenda de origem, os animais eram mantidos em campo nativo com controle parasitário pela administração de produtos à base de ivermectina e abamectina. Os animais trazidos à nova propriedade eram destinados à reprodução e cinquenta estavam prenhas. Vinte dias após o transporte, os animais apresentaram dificuldade locomotora, tremores musculares, agressividade, além de febre, fezes e urina de coloração escura. Os bovinos foram vacinados contra clostridioses, carbúnculo hemático e tratados com antimicrobianos (penicilinas) sem melhora do quadro clínico. Vinte e oito animais morreram no período de cinco dias.

Durante visita à propriedade, alguns animais manifestavam sinais neurológicos, todos apresentavam elevada carga de $\boldsymbol{R}$. (Boophilus) microplus e bovinos mortos foram vistos no pasto. $\mathrm{Na}$ necropsia de quatro animais, observaram-se mucosas pálidas e com petéquias, esplenomegalia acentuada, fígado aumentado com bordos arredondados e amarelado, vesícula biliar com parede edemaciada e repleta com bile grumosa. Os rins estavam vermelhoescuros (Figura 1A) e a bexiga continha urina cor de vinho tinto (Figura 1B). O epicárdio e endocárdio apresentavam hemorragias. No encéfalo, observou-se coloração róseo-cereja no córtex telencefálico, cerebelar e corpo estriado (Figura 1C). Em esfregaços teciduais do córtex encefálico, havia capilares repletos de hemácias, contendo estruturas basofílicas, solitárias ou pareadas, de aproximadamente $2 \mu \mathrm{m}$ de diâmetro, compatíveis com B. bovis (Figura 1D). Histologicamente o córtex encefálico apresentou congestão e grande quantidade de eritrócitos, contendo organismos basofílicos compatíveis com $\boldsymbol{B}$. bovis. Além de edema perivascular e perineuronal, havia também nefrose hemoglobinúrica, necrose hepática paracentral, bilestase canalicular e congestão esplênica.

Os demais bovinos foram medicados com dipropionato de imidocarb, no dia da realização das necropsias, baseando-se no diagnóstico macroscópico presuntivo. Segundo o proprietário, após o tratamento os animais que manifestavam sinais clínicos iniciais da doença se recuperaram e nenhum outro adoeceu. Dois meses após o surto, o proprietário optou por enviar os animais para abate por receio de novas perdas. $\mathrm{O}$ diagnóstico de babesiose cerebral foi baseado nos dados clínico-epidemiológicos, alterações patológicas observadas e na visualização de $\boldsymbol{B}$. bovis nos eritrócitos em capilares no esfregaço de córtex cerebral.

A babesiose cerebral é descrita em áreas de instabilidade enzoótica como doença mais frequente nos meses de verão e outono, principalmente, em raças européias e suas cruzas, em animais com idade média de 3 anos (ALMEIDA et al., 2005; RODRIGUES et al., 2005). O Rio Grande do Sul é área instável 


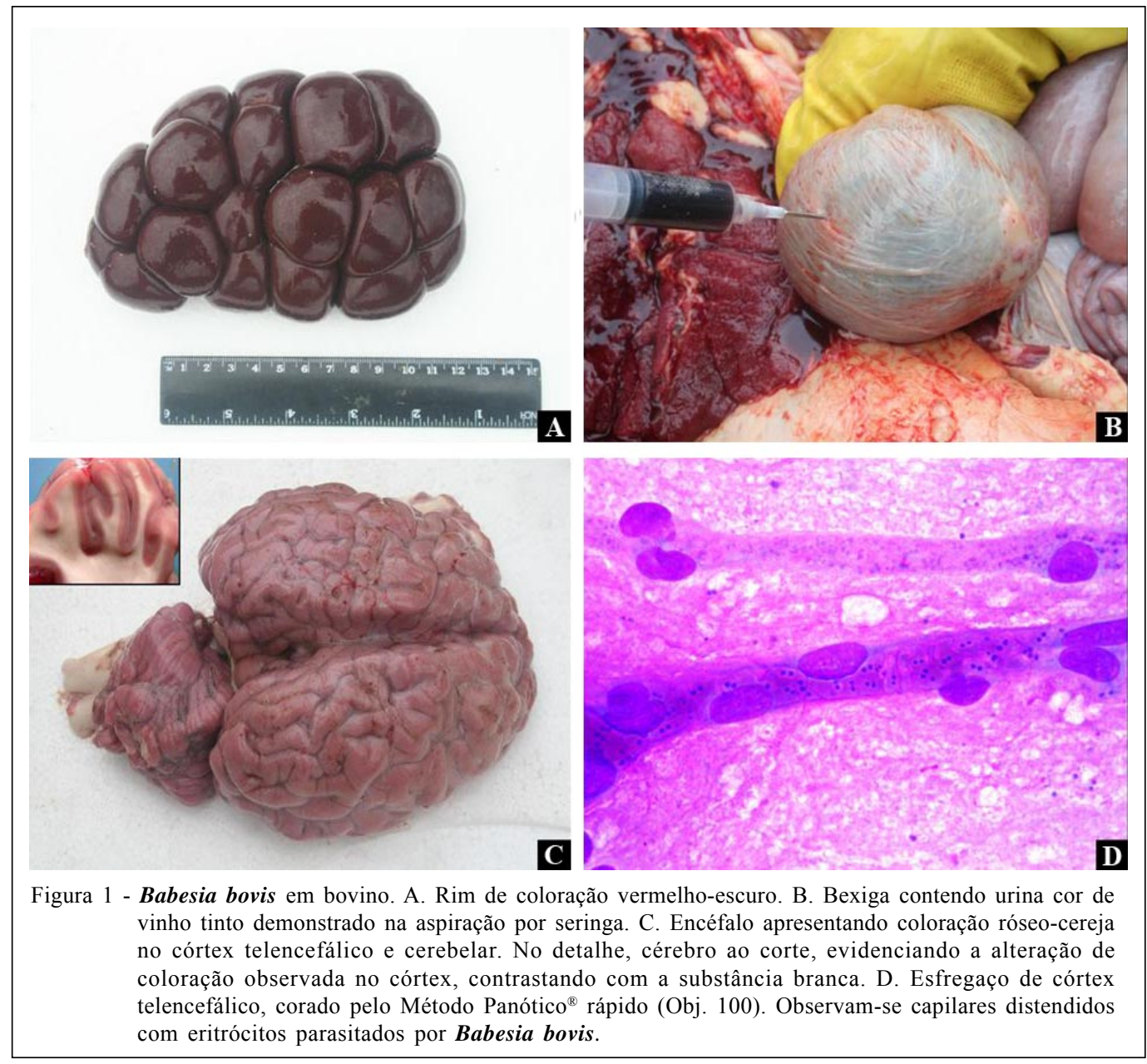

enzooticamente tanto para Babesia sp., como para seu vetor o R. (Boophilus) microplus (FARIAS, 2001; RODRIGUES et al., 2005). A epidemiologia do surto em questão vem corroborar com os estudos anteriormente realizados e reforçar a importância da doença na região.

É provável que esses animais não apresentassem imunidade adequada contra o agente por serem mantidos sob rigoroso controle parasitário não sendo expostos ao $\boldsymbol{R}$. (Boophilus) microplus e Babesia bovis por certo período (De VOS, 2004; GONÇALVES, 2000).

Considerando o período de permanência dos bovinos na nova propriedade, houve coincidência do inicio da manifestação clínica com o término do período de incubação relatado para o agente (RADOSTITS et al., 2002), indicando que a infecção ocorreu na introdução dos animais.

Os sinais clínicos e achados patológicos observados neste caso são comuns a casos de infecção por B. bovis, descritos por outros autores (ALMEIDA et al., 2005; RODRIGUES et al., 2005). Os sinais clínicos e lesões são decorrentes da parasitose de eritrócitos e hemólise (BARROS et al., 2006). Os eritrócitos parasitados acumulam-se em vasos de pequeno calibre da substância cinzenta, aderem-se uns aos outros e ao endotélio vascular causando estase e obstrução do vaso, levando a alterações degenerativas de anóxia e por sinais neurológicos observados (De VOS, 2004).

A observação macroscópica do encéfalo nos casos de babesiose por B. bovis, apresentando córtex de coloração róseo-cereja é fundamental para o diagnóstico post-mortem. É considerada característica de babesiose cerebral, permitindo o diagnóstico já na observação macroscópica (De VOS, 2004; BARROS et al., 2006). Essa coloração é devida ao acúmulo de eritrócitos parasitados, em vasos de pequeno calibre e ocorre na substância cinzenta pelo maior número desse tipo de vasos em relação à substância branca (CALLOW \& McGAVIN, 1963).

A predileção da $\boldsymbol{B}$. bovis por vasos de pequeno calibre, diferentemente da $\boldsymbol{B}$. bigemina, que é vista em maior quantidade na circulação geral, é responsável pela eficiência do esfregaço de córtex 
cerebral como método diagnóstico da babesiose cerebral (RODRIGUES et al., 2005; BARROS et al., 2006). No surto relatado, o diagnóstico foi estabelecido rapidamente pelo exame de esfregaços do córtex cerebral, ressaltando a sua eficiência para o diagnóstico.

$\mathrm{O}$ diagnóstico precoce e a rápida terapia babesicida são fundamentais para obter recuperação, porém, em casos com anemia severa, hemoglobinúria e sinais neurológicos, o prognóstico é desfavorável (CARLSON, 2006). A realização do tratamento preventivo neste caso impediu que novos animais adoecessem e permitiu cura dos animais com sinais clínicos iniciais.

Devido às manifestações neurológicas e morte rápida observadas nos casos de babesiose cerebral, essa, frequentemente, é confundida com outras doenças do sistema nervoso de ruminantes, como a raiva. Um conhecimento da epidemiologia, sinais clínicos e lesões são fundamentais para o diagnóstico e tratamento adequado.

\section{REFERÊNCIAS}

ALMEIDA M.B. et al. Tristeza parasitária bovina na região sul do Rio Grande do Sul: estudo retrospectivo de 1978-2005. Pesquisa Veterinária Brasileira, v.26, p.237-242, 2005.
BARROS, C.S.L. et al. Doenças do sistema nervoso de bovinos no Brasil. Montes Claros: Vallée. 2006. 207p.

CALLOW, L.L.; McGAVIN, M.D. Cerebral babesiosis due to Babesia argentina. Australian Veterinary Journal, v.39, p.15-21, 1963.

CARLSON, G.P. Doenças do sistema hematopoiético e hemolinfático. In: SMITH, B. P. Medicina interna de grandes animais. São Paulo: Manole. 2006. Cap.35, p.10391084 .

De VOS, A.J. et al. Bovine babesiosis. In: COETZER, J.A.W.; TUSTIN, R.C. Infectious diseases of livestock. Cape Town: Oxford, 2004. V.1, cap.25, p.406-424.

FARIAS, N.A.R. Tristeza parasitária bovina. In: RIETCORREA, F. et al. Doenças de ruminantes e eqüinos. São Paulo: Varela, 2001. p.35-42.

GONÇALVES P.M. Epidemiologia e controle da tristeza parasitária bovina na região Sudeste do Brasil. Ciência Rural, v.30, p.187-194, 2000.

RADOSTITS, O.M. et al. Clínica Veterinária, Um tratado de doenças dos bovines, ovinos, suínos, caprinos e eqüinos. 9.ed. Rio de Janeiro: Guanabara Koogan, 2002. p.1156-1163.

RODRIGUES, A. et al. Babesiose cerebral em bovinos: 20 casos. Ciência Rural, v.35, p.121-135, 2005.

SOARES, C.O. et al. Soroprevalência de Babesia bovis em bovinos na mesorregião Norte Fluminense. Pesquisa Veterinária Brasileira, v.20, p.75-59, 2000. 